\title{
The Conduction of Geotropic Excitation in Roots.
}

\author{
BY
}

R. SNOW

(Research Fellow of Magdalen College, Oxford).

With four Figures in the Text.

ASES have long been known in which stimulus striking on one part of a plant organ leads to a responsive movement in another part: we have to suppose that the excitation set up in the perceptive region is conducted along the plant organ to the region of response. Such conduction seems to offer special opportunities for investigating what is the nature of the excitation conducted. But further interest attaches to those cases where the responsive curvature is carried out in a direction determined by the direction of the stimulus. For in these the intercalated phase of conduction seems to make it possible to examine in what way the direction of stimulus thus determines the direction of response.

Amongst the best-known plant organs which show such conduction are roots and the so-called cotyledon of grass seedlings. In these, as shown by Ciesielski for the former and Rothert (1896) for the latter, excitation can be conducted back from the tip to produce a curvature in the elongating region.

A great advance was made when it was discovered by Boysen-Jensen (1913) that in the case of the etiolated cotyledon of the Oat, Avena sativa, such conduction can take place through a layer of gelatine. For if the tip is cut off and stuck on again with gelatine, and then excited by stimulus of light, while the lower zones are kept darkened, responsive curvature towards the light will follow in the darkened lower region. This has been confirmed for various other grasses by Páal (1918), and further shown to hold for traumatic stimulus in many other seedlings (Stark, 1921).

It therefore occurred to the writer to investigate by similar methods the old problem of the conduction, from root-tip to elongating region, of the excitation set up in the tip by the stimulus of gravity.

[Annals of Botany, Vo1. XXXVII. No. CXLV. January, I923.] 


\section{Methods.}

The experiments were made on roots of Vicia'Faba, the Broad Bean. The beans were germinated in moist sawdust. The tips were cut off at $2 \mathrm{~mm}$. from the vegetative point. While being cut, they were held horizontal for a few seconds, but in a plane at right angles to that in which they were aftewards pinned. For success in the experiment, certain small details must next be attended to. A Io to 15 per cent. solution of gelatine was found the best strength. This was sterilized by boiling and a very small drop of it applied warm to the end of the stump with a sterilized brush: excess of gelatine spoils the result. The tip can then be picked up with another slightly moistened brush and replaced. The surface tension of the gelatine pulls it back into position and ensures a good fit. The parts next to the cut must not be covered with excess moisture, or the gelatine will diffuse away: nor must they be quite dry, or the joint may crack open at the edges. The gelatine should not flow over on to the sides of the stump. Roots 20 or $25 \mathrm{~mm}$. long were found to serve the best. They were placed horizontal after operation, in moist boxes in such a way that their geotropic curvatures should be at right angles to the plane of the cotyledons, for, as shown by Sachs (1871), in this plane the root is steady, but in the plane of the cotyledons it nutates strongly. The gelatine solidifies after a varying time: in several roots that had responded well, it was examined in section under the microscope after twenty-four or fortyeight hours and found to form a uniform layer about $50 \mu$ thick. There had been no growth of the cells to form contact through the layer.

Most of the experiments were made with beans harvested nearly a year previously. Beans harvested in August and used in August and September were found less suitable, as they excrete so much water from the end of the stump that the gelatine is apt to be washed away. The various operations were made with the help of a watchmaker's lens.

The results of all experiments were recorded by drawing.

\section{Section I. Conduction of Geo-excitation through a Gelatine Layer.}

In the following experiments, only curvatures in the elongating region are considered. The various displacements that often take place at the base of the root are here omitted as due to other causes.

\section{(a) Controls.}

I. Thirty-two roots were decapitated and the ends of the stumps painted with gelatine, but the tips not replaced. Roots laid horizontal. After fifteen to twenty-four hours, 27 had not curved at all, 4 had curved down very slightly, I had curved down strongly. Even after decapitation, therefore, a few roots curve down. 
2. Five roots were decapitated, the tips killed by boiling, and stuck on again with gelatine. Roots laid horizontal. After twenty-four hours none had curved. Replacement of a dead tip has no effect.

(b) Tips replaced with Gelatine.

3. In all 76 roots were decapitated at $2 \mathrm{~mm}$. from the vegetative apex, and the tips stuck on again with gelatine. They were then placed horizontal. After fifteen to twenty-four hours, 45 curved downwards, 3I remained straight.

4. In certain earlier experiments, $I_{3}$ roots were decapitated at $2 \mathrm{~mm}$.

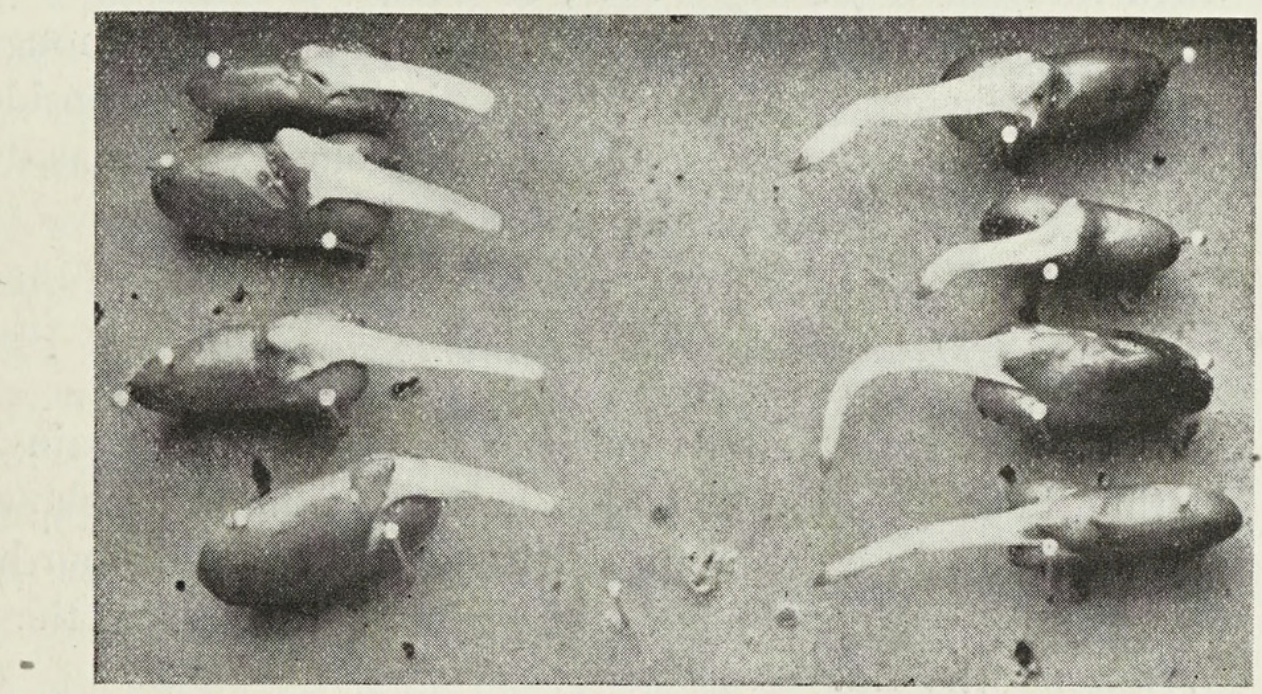

FIG. I.

from the end of the root cap, and the tips replaced with gelatine. They were placed horizontal. After fifteen to twenty-four hours, 9 curved down, 4 remained straight.

The extent of curvature in Experiments 3 and 4 varied from a slight curve to one of $90^{\circ}$. Curves of about $30^{\circ}$ were the commonest. Intact roots laid horizontal for comparison were often found not to curve through more than $45^{\circ}$.

Those roots which failed to curve often showed an enlargement at the end of the stump: this enlargement is also shown by decapitated roots without the tips replaced. But those that curved down usually did not show this enlargement, or showed it to a less extent. This suggests that in them the gelatine had made proper connexion between stump and tip, but that in those which failed to curve it had not made such connexion.

To show the extent of curvature obtained, a favourable experiment is illustrated (Fig. I). This represents a complete set of roots, operated on at one time. The four roots on the left were simply decapitated, and have been slightly displaced downwards from the base, but have scarcely curved 
in the elongating region. The four on the right, with tips replaced, have curved down to different extents.

- The above results should leave no doubt that replacement of the tip does lead to geotropic curvature.

Attempts to produce geotropic curvatures by cutting off the tip, and attaching it in a horizontal position to a glass slide while the

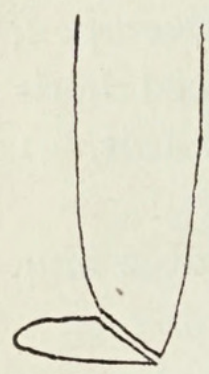

FIG. 2. stump remained vertical and then replacing the tip, were not successful. This is, perhaps, not surprising, since the tips must have been under very abnormal conditions. Attempts were also made to present the tip only to gravity, without presenting the stump, by cutting off the tip obliquely and then rotating it through $180^{\circ}$, as shown in Fig. 2. But the results, though favourable, were not pronounced enough to be convincing. Reasons will be given later for considering that the results of this section can scarcely be explained except as due to conduction of excitation from tip to elongating region.

\section{Section 2. Replacement of Tips in Anomalous Positions.}

5. Nine roots were decapitated and the tips stuck on again with gelatine in a position covering half the stump, as shown in

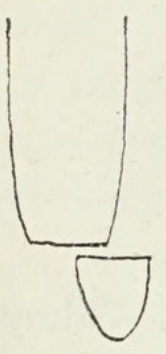

FIG. 3.

Fig. 3. They were then kept vertical. After twenty-four hours, 5 were still straight and 4 slightly curved towards the side covered by the tip.

6. Six roots were decapitated, the tips killed by boiling and then stuck back, covering half the stump, as above. After twenty-four hours, 2 were still straight, 3 were curved slightly towards the side covered by the tip, and I strongly so curved.

It would seem natural to explain this result as due to some substance diffusing from the dead tip, passing straight up the side of the stump covered by the tip, and retarding its growth.

7. The results of experiments to be referred to later will show that geotropic response can be brought about by conduction of excitation along either the upper or the lower half of the root alone. In the case of the lower half, if such excitation travels back by a straight path from the tip (as we shall find reason to believe to be the case), then it must be of such a kind as to cause retardation of growth in the lower half of the responding zone, which is affected by it.

If, then, the tip is stuck back so as to cover half only of the end of the stump (as in the last two experiments), and the root is then laid horizontally with that side of the stump that is covered by the tip uppermost (Fig. 4), we should expect a similar retarding influence to be transmitted now along the upper side of the stump, and so cause it to bend up. Unfortunately, it 
is difficult to know just how much overlap to allow in order to ensure the best connexion of the conducting tissues. In all, 20 roots were used for this experiment. Of these, after twenty-four hours, I 2 remained straight, 2 bent well up, 4 slightly up, and 2 slightly down. But since such roots, even if kept vertical, tend to bend

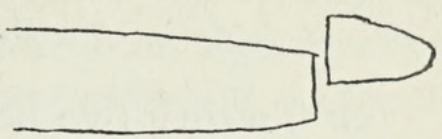

FIG. 4. slightly towards the side on which the tip is placed (cf. Experiment 5 above), such results are insufficient, even after allowance has been made for the slight sensitivity of the decapitated stump.

\section{Section 3. The Paths of Conduction.}

If excitations leading to tropic responses can be conducted through gelatine, this would seem, as pointed out by Páal (1918), to exclude any theory by which they consist in the passing on of any kind of induced protoplasmic polarity. Such a theory has been put forward by Fitting (1907) chiefly to explain certain experiments which seemed to show that in the cotyledon of Avena, after incisions had been made more than half-way through from opposite sides, photo-excitation could still pass down by a sinuous path from the tip to the responding region and there bring about phototropic response.

A simpler view of the relation between conduction and response would be that curvature in a certain direction is due not to any polarized nature of the conducted excitation, but to the fact that unequal intensities of excitation are conducted along the two sides of the organ, and so set up differences in rate of growth in the responding zone. These unequal intensities of excitation would in turn have been due to the unequal effects of the ${ }^{*}$ stimulus on the two sides of the perceptive region.

If we adopt this view, it will clearly be necessary to suppose also that the excitation is conducted only in straight lines: for otherwise the difference set up between the two sides of the perceptive region would be obliterated before the excitation could reach the responding region. Thus any evidence of conduction along a sinuous path would seem to make it necessary to reject any explanation along these lines, and to adopt one similar to Fitting's : for no other would seem possible.

Some, however, of his results with Avena have been doubted by later investigators (cf. Páal, 1918, p. 444 seq.).

In the case of roots, also, Pollock (1900) and Fitting (1907, p. 23. I seq.) have carried out experiments suggesting that traumatic excitation could be conducted tortuously around incisions. But apparently nothing was done to exclude conduction by diffusion straight across the cuts instead of round their margins. The question, therefore, seemed to need re-investigating. The case of geotropism was taken first for investigation, as the traumatic curvatures obtained appeared to be generally less vigorous. 


\section{Snow.-The Conduction of Geotropic Excitation in Roots.}

\section{Mica Slips inserted from one Side.}

8. Twenty-two beans were taken, and a single transverse cut made just half-way through, at $2 \mathrm{~mm}$. behind the vegetative apex. A slip of mica was slid into the cut. They were then pinned with the roots vertical. After twenty-four hours, eleven remained straight, one bent slightly away from the cut, nine bent slightly towards the cut, one bent strongly towards the cut.

From this it is clear that the traumatic stimulus tends to produce a slight positive curvature.

9. Six beans were taken, treated as in the last experiment, and then pinned with the root horizontal and the cut and mica slip on the upper side. All curved clearly down in the responding zone.

Io. Nine beans were taken at one time and treated in the same way, but pinned with the root horizontal and the cut and mica slip on the lower side. Two remained straight, one curved slightly down, six curved strongly down, making sharp curves of $60^{\circ}$ or $70^{\circ}$ in the responding region. These curves were obviously altogether different from those in Experiment 8 .

II. Fourteen beans were taken, treated in the same way, and pinned so that the mica slips were inserted laterally in the horizontal root. Ten remained straight, two curved slightly down, two curved strongly down.

From the results of Experiments 9 and 10 it is clear that after connexion between tip and responding zone has been broken to a depth of half-way through the root, either from above or from below, the geotropic excitation can be conducted back along the remaining intact half. This seems to happen more easily when the lower half is left intact, since with other less vigorous roots curvature often did not occur when it was the upper side that was intact, though it did when the lower side was intact. The case of the intact lateral half (Experiment II) is more doubtful: possibly the excitation is transmitted successfully, but response becomes difficult if only a lateral half of the responding zone is affected.

\section{Mica Slips inserted from two Opposite Sides.}

I2. Twenty-one beans were taken, and cuts made just half-way through the roots from opposite sides. One was at $2 \mathrm{~mm}$. behind the vegetative apex, and one at $2.75 \mathrm{~mm}$. behind. Mica slips were inserted. The beans were pinned with the roots horizontal, and the cuts one on the upper and one on the lower side. Only curvatures occurring above the second cut were considered. Sixteen remained straight, one bent well down, three bent slightly down, and one bent slightly up. 
I3. Twenty-four beans were treated as in Experiment I2, but pinned so that the two cuts and mica slips were lateral on the horizontally placed root. Twenty-one remained straight, one bent down, two bent slightly down. If the results of these two experiments are compared with those for decapitated roots in Experiment I, it will be seen that there is no significant difference.

It thus appears that the geotropic excitation cannot be conducted in a sinuous path so as to pass round two cuts made from opposite sides and filled with mica slips. There is indeed no reason to suppose that it travels otherwise than in straight lines. Further, since, as shown in Experiments 9 and Io, geo-excitation can be effectively conducted back along either an upper or a lower half-root alone, it appears that these excitations, if they travel in straight lines, must be of two different kinds, one in the upper half leading to relative increase of growth, and one in the lower half leading to relative decrease. A similar state of things appears to hold for the responses to light and gravity of the Avena cotyledon. For there, according to Purdy (1921), photo-excitation can travel down from the tip either by way of the side farthest from the light alone, or, less easily, by the side towards the light alone, and in either case can still bring about positive curvature. Similarly, geo-excitation can travel back from the cotyledon tip by either the lower side or, less easily, the upper side alone. She reports, however, no experiments on the critical question whether in Avena conduction can or cannot take place by a sinuous path.

\section{Discussion.}

A decapitated root, as is well known, does not curve down in response to gravity, or only seldom. Yet this is not because it is unable to respond, for if the root is first exposed to gravity while intact, and then decapitated, it curves down normally. The simplest explanation of this, as suggested by Charles Darwin, is that the decapitated root is unable to perceive the stimulus of gravity, since perception takes place in the tip. In conformity with this, we have found that if, after decapitation, the tip is stuck on again with gelatine, the reconstituted root is able to perceive the stimulus of gravity and respond to it. It is, then, natural to suppose that the tip perceives the stimulus normally and transmits back excitation through the gelatine layer.

And nothing now stands in the way of this explanation. For, firstly, it is beyond doubt that excitation can be conducted through a gelatine layer, as in the case of the Avena cotyledon; and, secondly, it can hardly be doubted now that in the intact root excitation due to stimulus of gravity is transmitted back from the tip. For, as further evidence of this, besides 
Czapek's well-known 'glass-boot' experiments (1895, p. 255 seq.) there is now Haberlandt's research (1908) by Piccard's rotation method. In this, various seedlings, including Vicia Faba, were fixed to a turn-table that could be rotated rapidly about a vertical axis. They were placed so that the roots pointed obliquely downwards at $45^{\circ}$ to the vertical, and so that the imaginary prolongation of the axis of rotation intersected the roots at a short distance behind the tip. In this way, the tip of the root on one side of the axis and the responding region on the other were exposed to transverse centrifugal forces in opposite directions. It was found that the responding region possessed a certain sensitivity, which was, however, marked by the greater effect transmitted from the tip, when the point of intersection was $\mathrm{I} .5 \mathrm{~mm}$. or more behind the tip.

But though it is thus probable that geo-excitation in the root can be conducted through gelatine, it is not easy to get such definite evidence of this as can be obtained when the stimulus is that of light or of wounding. For in these cases it is easy, after the operation, to stimulate the tip of the organ without stimulating the responding region; but with gravity this cannot easily be done, and the attempts to do so described earlier were scarcely successful. There remains, therefore, another possible explanation. The responding region of the root, as has been shown by Haberlandt, is itself slightly sensitive to gravity. It might be, then, that the effect of decapitation was to make perception impossible, not only by removing the highly sensitive tip, but also by destroying the sensitivity of the responding region by some effect of wound shock or correlative disturbance. When, therefore, the tip was replaced, it might bring about response, not by transmitting back geo-excitation through the gelatine, but by transmitting some influence that restored the sensitivity of the responding region.

A process similar to this seems indeed to occur in the Avena seedling. For in this and in other grass seedlings, so long as they are intact, the lower zones of the cotyledon, as shown by Rothert (1896), are to some extent sensitive to light. But after decapitation they become quite insensitive. It has now been shown by Brauner (1922, p. 540) that in Avena, if the cotyledon tip is cut off and kept in the dark, and the lower zones exposed to stimulus of light, and if the seedling is then put in the dark again and the tip replaced, a positive curvature follows. The replacement of the tip must, then, have restored the sensitivity of the lower zones.

It is remarkable, however, that in the grass seedlings it is only complete removal of the tip that makes the lower zones insensitive; deep wounds made in ido not have this effect. If, then, similar relations held for the root, we should expect it to bend when laid horizontal even after the infliction of a wound on the tip. But, on the contrary, it is well known that any deep cut made in the tip makes the root insensitive to gravity. It does not seem, then, that there is anything in the root similar to this sensitivity of 
the lower zones of the grass cotyledons when connected with their tips, and loss of sensitivity in their absence. It seems rather that when the root tip is replaced with gelatine it must bring about response of perceiving the stimulus of gravity and transmit back the true geo-excitation through the gelatine, though a definite proof of this cannot yet be given.

Incidentally, this result of Brauner's shows, as he points out, that what is lacking in the decapitated cotyledon is neither the power of perceiving nor that of responding, but some intermediate phase of the tropistic processes. To call it insensitive is therefore perhaps misleading.

As to the light which the gelatine experiments throw on the nature of conduction, the processes most naturally suggested as capable of passing through the gelatine are, as pointed out by Páal, the diffusion of soluble substances and the electric current. The latter he considers excluded in the case of Avena, as conduction was not found to take place through a platinum plate. But this conclusion seems hardly convincing, firstly because metals in contact with living tissues polarize very rapidly, and secondly, because short-circuiting would occur in the metal plate so that no current production in the tissues on one side of it could have any effect on those on the other side.

Still, it certainly seems more likely that such conduction through nonliving media is due to diffusion, especially since Ricca (1916), working with Mimosa, and Stark (1921, p. IIO), with Avena, appear to have extracted such soluble stimulating substances.

Naturally, it does not at all follow that throughout all its course the conduction is effected by any such purely physical process. Indeed, it is most unlikely that it should be, in view of Fitting's experiments (1907, p. 219 seq.) on the effects of the local application of warmth and anaesthetics to the conducting region in Avena.

These agents were often found to prevent conduction, although not killing the tissue. In this respect Avena differs strikingly from Mimosa, in which conduction, now known to take place in the wood, can pass through stretches of anaesthetized or even dead stem.

It seems, then, that in conduction of the Avena type the living tissues must in some way be actively concerned; and accordingly it has been suggested (Páal, 1918, p. 432) that the conduction may be a composite process, in which excitation at one point leads to the production of soluble stimulating substances, which diffuse away to neighbouring points of the tissue and excite them in turn, with production of more of the substances, and so on. The purely physical part of this process might be able to pass through a layer of gelatine, but yet not be able to travel far through the living tissue unless aided by renewal of the excitation.

But if, as the experiments on the paths of conduction have led us to suppose, there are two kinds of conducted excitation, one on the concave 
side leading to decrease of growth, and one on the convex side leading to increase, then clearly we need first to determine whether both of these can pass through the gelatine, or one of them only. It is hoped shortly to investigate this question, for, until it is settled, suggestions as to the relation between conduction in the gelatine and conduction in the living tissue are perhaps premature. Meanwhile, in Avena the feeble response when conduction is only possible by the near side, and the stronger response after decapitation and replacement of the tip with gelatine, seem to indicate that at least the excitation conducted by the far side can pass through the gelatine.

It may, however, be noted that Brauner (1922) has observed in the Avena cotyledon a vigorous protoplasmic streaming, which might enable soluble substances to pass down it much faster than they could by simple diffusion.

\section{SumMary.}

I. If the tips of decapitated roots of Vicia Faba are stuck on again with gelatine, the roots in most cases become again capable of bending down in response to gravity. It appears that excitation set up in the tip must be conducted back through the gelatine.

2. If a cut is made half-way through the root from one side, at a point $2 \mathrm{~mm}$. from the vegetative apex, and a mica slip is inserted into the cut, to prevent diffusion across it, the root can still respond to gravity by bending down in the elongating zone when placed horizontal, whether the cut be on the upper or the lower side. Hence either the upper or lower side alone can conduct back excitation from the tip.

3. If two mica slips are inserted half-way through from any two opposite sides at $2 \mathrm{~mm}$. and $2.75 \mathrm{~mm}$. from the apex, and the root placed horizontal, it does not curve down, or no more frequently than a decapitated root. Only curvatures above the second cut are here referred to. The excitation cannot therefore be effectively conducted back from the tip by a sinuous path.

These results are briefly discussed.

I wish to thank Professor Sir Frederick Keeble for encouragement during this investigation.

The Department of Botany, OXFORD,

October 1922. 


\section{REFERENCES.}

Boysen-Jensen, P. (1913): Über die Leitung des phototropischen Reizes in der Avenakoleoptile. Ber. d. d. Bot. Ges., xxxi. 559 .

Brauner, Leo (1922): Lich tkrïmmung und Lichtwachstumsreaktion. Zeitschr. f. Bot., xiv. 497 . CzAPEK (1895) : Untersuchungen über Geotropismus. Jahrb. f. wiss. Bot., xxvii.

Fitting (1907): Die Leitung tropistischer Reize in parallelotropen Pflanzenteilen. Jahrb. f. wiss. Bot., xliv.

Haberlandt (1908) : Utber die Verteilung der geotropischen Sensibiiität in der Wurzel. Jahrb. f. wiss. Bot., xlv.

PÁAL (1918): Über phototropische Reizleitung. Jahrb. f. wiss. Bot., xlviii.

Pollock (1900): The Mechanism of Root Curvature. Bot. Gaz., xxix. I.

PURdy (1921): Studies on the Path of Transmission of Stimuli in the Coleoptile of Avena. Det Kgl. Danske Videnskabernes Selskab, Biologiske Meddelelser, iii. 8.

RicCA (1916): Soluzione di un problema di fisiologia. Nuovo Giorn. Bot. Ital., xxiii, 5 I.

(1916) : Solution d'un problème de physiologie. Arch. Ital. d. Biol., lxv. 2 Ig.

Rothert (1896) : Über Heliotropismus. Cohn's Beitr. z. Biol. d. Pflanz., vii.

SACHS (1873): Ueber das Wachstum der Haupt- und Nebenwurzeln. Arb. d. Bot. Inst. Würzb., i. $3^{8} 5$.

STARK (1921): Stndien über traumatotrope und haptotrope Reizleitungsvorgänge. Jahrb. f. wiss. Bot., $1 \mathrm{x}$. 


\section{$2 \mathrm{BHL}$ Biodiversity Heritage Library}

Snow, R. 1923. "The conduction of geotropic excitation in roots." Annals of botany 37, 43-53. https://doi.org/10.1093/oxfordjournals.aob.a089835.

View This Item Online: https://www.biodiversitylibrary.org/item/270686

DOI: https://doi.org/10.1093/oxfordjournals.aob.a089835

Permalink: https://www.biodiversitylibrary.org/partpdf/319066

\section{Holding Institution}

New York Botanical Garden, LuEsther T. Mertz Library

\section{Sponsored by}

BHL-SIL-FEDLINK

\section{Copyright \& Reuse}

Copyright Status: Public domain. The BHL considers that this work is no longer under copyright protection.

This document was created from content at the Biodiversity Heritage Library, the world's largest open access digital library for biodiversity literature and archives. Visit BHL at https://www.biodiversitylibrary.org. 